\title{
Renal function in the third year among very low birth weight infants fed by supplemental proteins
}

\author{
Arash Bordbar, Azade Noroozi Vahid, Mandana Kashaki \\ Shahid Akbarabadi Clinical Research Development Unit, Iran University of Medical Sciences, \\ Tehran, Iran \\ This article is distributed under the terms of the Creative Commons Attribution Noncommercial License (CC BY-NC 4.0) which permits \\ any noncommercial use, distribution, and reproduction in any medium, provided the original author(s) and source are credited.
}

\begin{abstract}
Very Low Birth Weight (VLBW) infants have higher nutritional needs than term infants. Energy and protein are two important factors influencing their growth. Breastfeeding is not enough to meet VLBW infants' needs, for this reason, complementary protein is required by them. Hence, the present study aimed at investigation of renal function among VLBW infants receiving complementary proteins. The study was conducted on two groups of intervention and control ( $n=18$ in each group) (Case study: VLBW infants born in Akbarabadi hospital of Tehran in 2014 2015). The intervention group includes 3 -year-old children who weighting less than 1200 grams at birth and have received protein supplementation at the course of NICU hospitalization, protein was added to maternal milk when the amount of milk reaches to $100 \mathrm{cc} / \mathrm{kg} / \mathrm{day}$, at this time parenteral nutrition was discontinued and the volume of feeding was increased $20 \mathrm{cc} / \mathrm{kg} / \mathrm{day}$ until reached to $150-180 \mathrm{cc} / \mathrm{kg} / \mathrm{day}$. We also added the fortifier to breast milk at this time. The fortification and the protein supplementation were stopped when the weight of the baby reached to 1500 grams. The control group was fed similar to the intervention group but had received no complementary protein. The renal function was evaluated by measuring such criteria as BUN, $\mathrm{Cr}, \mathrm{ALB}$ and U/A. After data collection, a statistical analysis was performed using SPSS software Ver. 22. Following to BUN evaluation, a significant correlation was seen between BUN and received protein $(\mathrm{p}$-value $=0.010)$. However, there was no significant correlation between $\mathrm{Cr}$ and received protein as well as mean values of the two groups (p-value=0.0766). Similarly, an insignificant correlation was found between the two groups following to investigation of ALB ( $p$-value $=0 / 257$ ), while the mean values of the two groups were similar. The both groups were also equal in U/A. The complementary protein increased the BUN with no effect on Cr, ALB and U/A, providing no impact on renal function. Therefore, complementary protein intake made no conflict in renal function.
\end{abstract}

Key Words: complementary protein, renal function, very low birth eight, infants, blood urea nitrogen, creatine, albumine

Eur J Transl Myol 30 (2): 304-310, 2020

Over the past few decades, improved care for premature infants has led to a significant increase in their survival rates, especially in infants born with a weight less than $1000 \mathrm{~g}$. Therefore, more attention is currently being paid to improving the long-term outcome and quality of life among such infants. ${ }^{1}$ The normal growth of the fetus in the womb is very rapid. For example, from the week 30 to 36 of gestation, the fetus's body weight doubles and there will be a significant differentiation in tissues. Providing quality and quantitative growth is a major challenge in infants whose nutritional linkage through funiculus is cut off prematurely. The purpose of feeding such infants is to keep their growth at the same rate as the intrauterine process. $^{2}$ These infants have higher nutritional needs compared to term infants. Energy and protein are the two important factors that affect growth, thus, one of the key goals of nutrition management is to facilitate their absorption. ${ }^{3}$ The newborn infants not received any protein will have a negative nitrogen balance and lose up to $1 \%$ of their protein reserves every day. ${ }^{4}$ In addition, recent studies report that insulin levels drop when there is amino acid deficiency, leading to hyperglycemia and hyperkalemia., ${ }^{5,6}$ On the other hand, the best food for premature infants is the breast milk. Other benefits of breastfeeding, in addition to nutritional benefits, include protecting the infant from many 


\section{Renal function in the third year of birth}

Eur J Transl Myol 30 (2): 304-310, 2020

infections, reducing sudden death syndrome and possibly long-term effects such as: lower risk of childhood or adolescent obesity and improved outcome of neurodevelopment. ${ }^{7}$ Therefore, after achievement of breast milk volume to $120 \mathrm{ml} / \mathrm{kg}$ of body weight, Human Milk Fortifier is recommended to be used to enhance breast milk with protein, calcium and phosphorus until infant weight reaches 2500 g. ${ }^{8}$ Furthermore, premature infants are subjected to physical growth retardation, metabolic abnormalities, and neurodevelopmental delay. This is while the amount of protein and other nutrients in breast milk is not enough to meet the extremely high needs of Very Low Birth Weight (VLBW) infants. Developmental failure is a common problem among the VLBW infants who are breastfed only. ${ }^{9-11}$ Ectopic growth restriction among infants with Extremely Low Birth Weight (ELBW) during admission to the Neonatal Intensive Care Unit (NICU) is a negative prognostic factor for long-term outcomes. Among ELBW infants, complementary nutrition should be given for growth to be equal to fetuses of similar gestational age. Proper growth and development (specifically in the brain) is dependent on protein intake. ${ }^{12,25}$ Given to whatever mentioned above, the necessity of VLBW infants' nutrition (breast milk plus complementary protein) and also the threats of renal dysfunctions among such infants as well as very limited investigations conducted in this field, the aim of this study was to investigate the long term impact of protein supplementation on renal function of under $1200 \mathrm{~g}$ bearth weighing infants in the third year of birth. This study was based on a RCT (was registered in IRCT) that designed to investigate the growth of newborns following supplemental protein used and the results was mentioned in a previous article, ${ }^{14}$ and after three years we designed the present study to evaluate the renal functional outcomes in that babies.

\section{Materials and Methods}

The present study is a clinical trial where infants weighing less than 1200 grams born at Akbar Abadi Hospital in 2014-15 (at the time of study, they were 3 years old) were investigated in two groups, one group being breast-fed plus HMF as well as complementary protein and the other group was fed by breast milk plus HMF. Intake of protein powder was 0.6-0.8g/day, whose brand is not mentioned due to the advertising aspect. They have received protein supplementation at the course of NICU hospitalization, protein was added to maternal milk when the amount of milk reaches to $100 \mathrm{cc} / \mathrm{kg} / \mathrm{day}$, at this time parenteral nutrition was discontinued and the volume of feeding was increased $20 \mathrm{cc} / \mathrm{kg} / \mathrm{day}$ until reached to $150-180 \mathrm{cc} / \mathrm{kg} / \mathrm{day}$. The fortification and the protein supplementation were stopped when the weight of the baby reached to 1500 grams The protein intake in all infants in the intervention group was the same and from one brand in our study. The control group was fed similar to the intervention group but had received no complementary protein. The inclusion criteria for participants were as follows: Birth weight less than 1200 in 2014-15, having parents' consent for participation and regular presence in the test sessions. The exclusion criterions were: To suffer a major disease preventing to achieve data, such as asphyxia, renal anomaly, cardiac anomaly, severe sepsis, necrotizing enterocolitis and renal failure at the time of hospitalization. The sample size was not required to be calculated in this study since renal function would be evaluated over a specified period of one year (age 3). The number of infants mentioned in

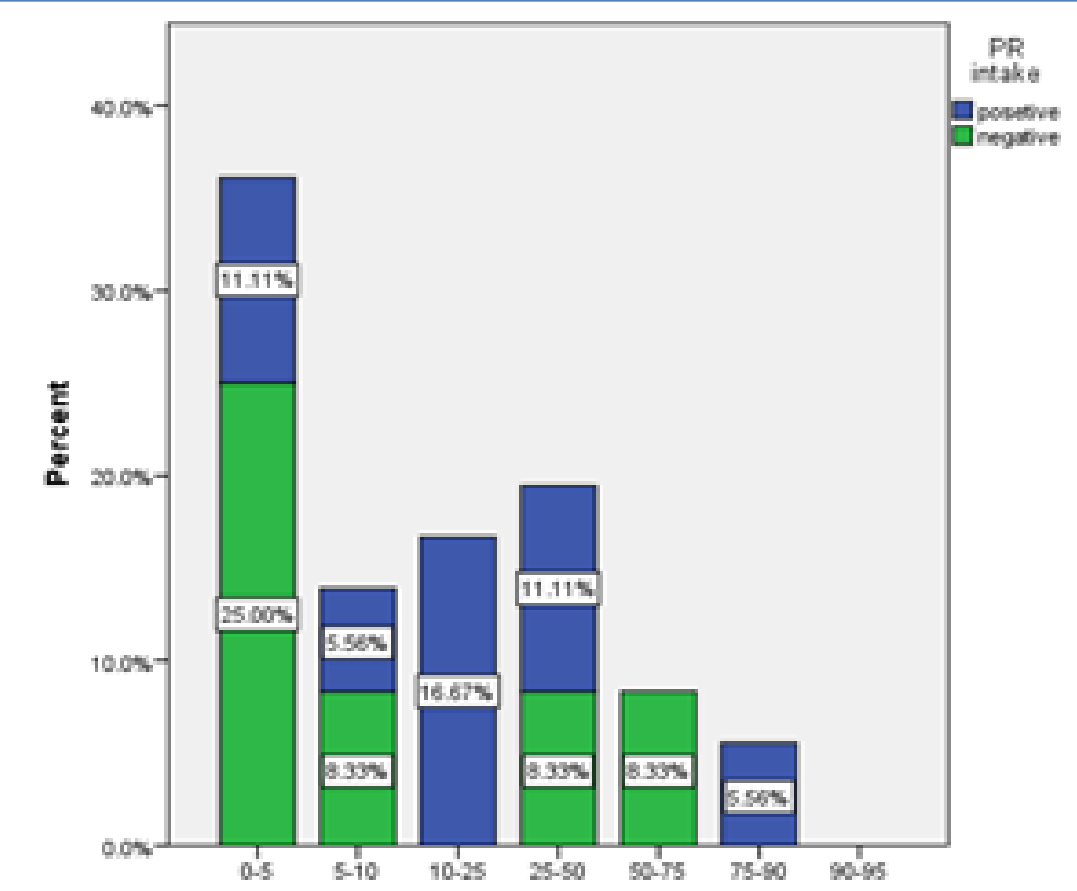

Fig 1. Diagram for current weight of participants 


\section{Renal function in the third year of birth}

Eur J Transl Myol 30 (2): 304-310, 2020

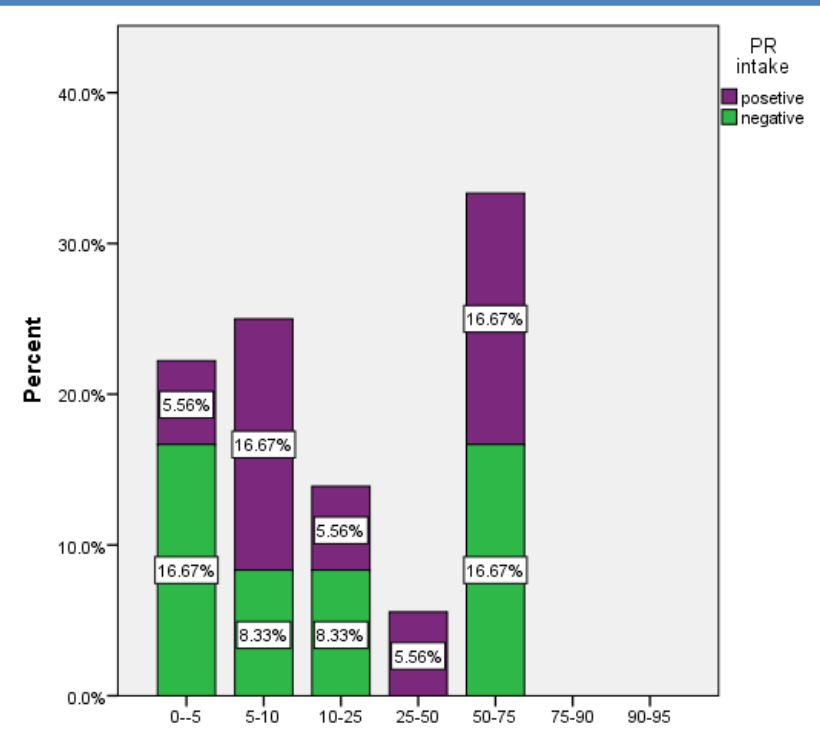

Fig 2. Diagram for current height of participants

the above two groups was in total 70 in 2014-15, but in this study, the numbers dropped to two groups of 18 . Indeed, we encountered drop of subjects due to several reasons, e.g., lack of access to infants, mistakes in call numbers, etc. As a result, 18 infants in each group were randomly enrolled in the present study. In the given day, the children were examined by the appropriate physician and their height and weight were measured. Afterwards, the relevant tests (BUN, Cr, U/A, Alb) were conducted at the hospital laboratory. These tests were considered to evaluate the renal function of the children at the age of 3 years with regard to protein intake during infancy. Each test is described briefly as follows:

- BUN, or Blood Urea Nitrogen test, measures the amount of urea nitrogen in the blood, showing how the kidneys work [21].
- Cr: Creatinine is a protein produced by metabolism in the muscles, which is excreted by the kidneys, and in association with BUN, helps evaluating renal function [22].

- Alb: Albumin is one of the proteins in the plasma that is produced by the liver. In renal failure, due to lack of protein reabsorption, it decreases in the blood [23].

- U/A: Urine analysis (urinalysis) for kidney tests [24] At the final step, after data collection, it was coded and imported into the software package SPSS Ver.22 for analysis. The results were expressed as mean and standard deviation (mean $\pm \mathrm{SD}$ ) for the quantitative variables and as percentages for the qualitative variables. Significance level was set to be less than 0.05. All patient data were analyzed by the statistical software as well as by chi-square and T-student statistical tests.

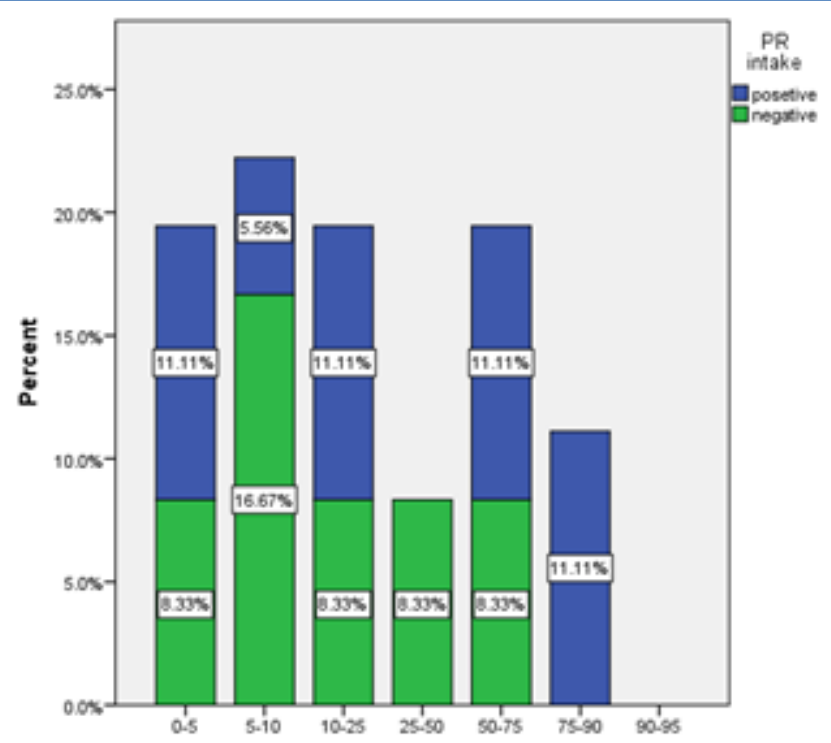

Fig 3. Diagram for current head circumference of participants 


\section{Renal function in the third year of birth}

Eur J Transl Myol 30 (2): 304-310, 2020

\section{Results}

Demography and general specifications

$30.56 \%$ and $69.44 \%$ of the cases were girls and boys, respectively. $42.77 \%, 36.11 \%$ and $16.61 \%$ of the cases were in the age 14-24 months, 24-34 months and 34-44 months, respectively. Cesarean delivery had been applied for all infants. At their birth, 22.22\%, 50\% and $27.78 \%$ controls were in the percentile 5-10. Additionally, $16.67 \%$ of the protein recipients were in the percentile $10-25.11 .11 \%$ of the former group and $8.33 \%$ of the latter group were in the percentile 25-50. Finally, 5.56\% of the intervention group members were in the percentile 75-90 (Figure 1). In terms of their current height, $16.67 \%$ of the intervention group members and $5.56 \%$ of the control group members were in the percentile 0-5.

Table 1. presents the results of BUN test in both control and intervention groups. $P=0.010$

\begin{tabular}{|c|c|c|c|c|c|}
\hline & Group & $\mathrm{N}$ & Mean & Std. Deviation & Std. Error Mean \\
\hline \multirow[t]{2}{*}{ BUN } & Intervention & 18 & 16.67 & 4.875 & 1.149 \\
\hline & Control & 18 & 13.00 & 2.910 & .686 \\
\hline
\end{tabular}

Table 2. presents the results of Creatine test in both control and intervention groups. $P=0.766$

\begin{tabular}{|l|l|l|l|l|l|}
\hline & \multicolumn{1}{|c|}{ Group } & \multicolumn{1}{c|}{$\mathrm{N}$} & \multicolumn{1}{c|}{ Mean } & \multicolumn{1}{c|}{ Std. Deviation } & \multicolumn{1}{c|}{ Std. Error Mean } \\
\hline Creatinine & Intervention & 18 & .800 & .2000 & .0471 \\
& Control & 18 & .783 & .1249 & .0294 \\
\hline
\end{tabular}

Table 3. presents the results of Albumine test in both control and intervention groups. $P=0.257$

\begin{tabular}{|l|l|l|l|l|l|}
\hline & & & & & \\
& PRintake & $\mathrm{N}$ & Mean & Std. Deviation & Std. Error Mean \\
\hline Albumin & Intervention & 18 & 4.456 & .3468 & .0817 \\
& & & 4.600 & .4029 & .0950 \\
\hline
\end{tabular}

Table 4. presents the results of Urinalaysis (U/A) test in both control and intervention groups.

\section{PRintake * Urinalaysis Crosstabulation}

\begin{tabular}{|c|c|c|c|}
\hline \multicolumn{4}{|l|}{ Count } \\
\hline & & Urinalaysis & \multirow[b]{2}{*}{ Total } \\
\hline & & Normal & \\
\hline \multirow[t]{2}{*}{ Group } & Intervention & 18 & 18 \\
\hline & Control & 18 & 18 \\
\hline \multicolumn{2}{|l|}{ Total } & 36 & 36 \\
\hline
\end{tabular}

According to the table above, the U/A was normal in both groups and no significant relationship was observed between the two groups. Given the normality of U/A, the p-value was not calculated.

of the babies had a weight of 750-900g, 900-1050g and $1050-1200 \mathrm{~g}$, respectively. In terms of their current weight, $11.11 \%$ of patients who received protein (intervention group) and $25 \%$ of those without protein intake (control group) were in the percentile 0-5. Also, $5.56 \%$ of intervention group members and $8.33 \%$ of
$16.67 \%$ of those received protein and $8.33 \%$ of those without protein intake were in the percentile 10-25. $5.56 \%$ of the former group members and $8.33 \%$ of the latter were in the percentile $10-25$. Lastly, $16.67 \%$ of those received protein and $16.67 \%$ of the controls were in the percentile 50-75 (Figure 2). In the realm of head 
circumference, about $11.11 \%$ of those, who received the protein and $8.33 \%$ of those without protein intake were in the percentile $0-5.5 .56 \%$ of protein recipients and $16.67 \%$ of non-protein recipients were in the percentile $5-10.11 .11 \%$ of the intervention group members and $8.33 \%$ of the control group members were in the percentile $25-50$. In the percentile $50-70$ there $8.33 \%$ of the non-protein recipients. In the percentile 75-90 were $11.11 \%$ of those, who received protein (Figure 3 ).

The results of each test were elaborated individually as presented in the Tables 1 to 4 . Considering the obtained $\mathrm{P}$-value, there is a significant relationship between BUN and protein intake among ELBW infants. The mean value of intervention group was significantly higher than that of controls. There was no significant relationship between $\mathrm{Cr}$ content and protein intake among ELBW infants with respect to the obtained p-value. According to the UPPER and LOWER limits, the first one was positive and the second was negative, the mean values of the two groups were not significantly correlated and were relatively equal. According to the obtained p-value, there was an insignificant relationship between ALB and protein intake among ELBW infants. According to the UPPER and LOWER limits, the first one was positive and the second was negative and the mean values of the two groups were not significantly correlated and were relatively equal. According to the table above, the U/A was normal in both groups and no significant relationship was observed between the two groups. Also, given the normality of U/A, the p-value was not calculated.

\section{Discussion}

In the present clinical trial, we evaluated the long-term consequences of supplementary protein intake on renal function of VLBW children. Three years after protein administration, these children's renal function was reevaluated. The intervention and control groups were matched according to the corresponding variables. The former group was composed of those, who have taken supplementary protein and the latter did not have such an experience. This evaluation was undertaken at age 3 yearso. From one hand, the necessity of protein intake as a supplementary has been proved beneficial for ELBW infants, ${ }^{13,14,25}$ but from another hand the renal function of premature and ELBW infants is of high importance since cases of renal dysfunction and decreased kidney size have been described after birth of premature and ELBW infants. ${ }^{20}$ However, to the best of our knowledge very low or even no study has been published to test if protein intake can make a significant impact on renal function of such babies. To this aim, four special tests of renal function assessment were chosen and conducted to answer the research question. Recent studies report that feeding premature infants with protein-rich diets will be accompanied by positive nitrogen balance, enhancing protein synthesis in the body, improving postnatal growth, improving cognitive function, and improving brain development. ${ }^{13,25}$ Kashaki et al., ${ }^{14}$ undertook an investigation on ELBW infants, where the infants were divided into two groups, randomly assigned to the group receiving diet containing supplemental protein and the other group receiving no proteins. Their findings indicated that the former group had better growth. ${ }^{14}$ Also, in a similar study, Mariani et al., ${ }^{15}$ reported that the increased content of protein intake in breast milk can result in short/long-term profits in the realm of neurodevelopment and growth among ELBW infants. Additionally, William argues that improving preterm infants' nutrition, either intravenous or enteral, following to the birth, will enhance protein balance and positive energy and also will promote longer neurodevelopmental results. Such profits were permanent, specifically to prevent chronic diseases. ${ }^{15}$ Accordingly, Morgan et al. reported that early and more energy and protein intake will result in faster head growth and enhanced head circumference among preterm infants. ${ }^{16}$ Meanwhile, Kumar and Sundaram found that breast milk cannot merely meet preterm infants' severe nutrient needs including vitamins, proteins, minerals, energy and trace elements. ${ }^{17}$ Ken et al., conducted a retrospective study in Osaca medical center. They evaluated the corrected BUN (CBUN) in the third year of birth among ELBW children in two groups according to Developmental Quotient (DQ) having one $\mathrm{DQ} \geq 80$ and the other group $\mathrm{DQ}<80$. During the study, between 1998 and 1999, 178 ELBW neonates with a gestational age of less than 28 weeks were admitted to the NICU. 32 of them died. Of the remaining 146 neonates, 37 were excluded from the study without Criteria exclusion (affecting cognitive function and BUN) except for the feeding factor. In this group, the modified BUN was measured using the MORO formula (CBUN: BUN $\times 0.5$ / serum creatinine). Finally, a curve of CBUN values was prepared between the days 28-84. This curve became an indicator to give extra protein. They concluded that the area under the CBUN curve could provide an estimate of whether the amount of protein given is sufficient and subsequently the evolution of preterm infants can be monitored through the CBUN level. ${ }^{18}$ Radmacher et al., argued that administration of amino acids during the life's first hours might be beneficial and safe ELBW infants, leading to disappearing symptoms of renal dysfunction. ${ }^{19}$ Because of disruption of organogenesis in a critical time of development, kidney size and nephron number are proved to be decreased among premature infants. This is while increased kidney injury from nephrotoxicity and hypoperfusion will give rise to structural and functional variations over time, thogh often unnoticed. ${ }^{20}$ Considering the obtained P-value (P-VALUE=0.010), a significant relationship was seen between BUN and protein intake among ELBW infants. This finding is in line with results of Bush A and Fleming $\mathrm{L},{ }^{18}$ showing that Corrected BUN (CBUN) can be an estimate of the proper amount of protein needed for growth in neonates. According to a study we did at the age of 3 years in preterm infants, protein supplementation in preterm 
infants had no effect on renal function, and only at the beginning of supplemental protein intake, an increased BUN was seen. ${ }^{14}$ There was no significant relationship between $\mathrm{Cr}$ content and protein intake among ELBW infants with respect to the obtained p-value (PVALUE=0.766), indicating no adverse effect on renal function. Unfortunately, no similar studies were found to confirm those findings. According to the obtained pvalue (P-VALUE=0.257), there was a not insignificant relationship between ALB and protein intake among ELBW infants, indicating no adverse effect on renal function. For this variable, there are no similar studies. The U/A was found to be normal in both groups and no significant relationship was observed between the two groups, indicating no adverse effect on renal function. Unfortunately, no similar studies were found to confirm that finding. As in many studies, we faced limitations, including very poor resources and investigations conducted on the impact of protein supplementation on renal function of ELBW infants and also lack of collaboration from some families of patients so that only half of the capacity was employed in present study. Given the low size of the populations, this topic needs to be conducted in a greater population at diverse medical centers and hospitals, even in the entire country.

Anyhow, according to our results, protein therapy in preterm infants causes a slight increase in BUN levels. It does not affect other renal parameters such as $\mathrm{Cr}$, ALB, and U/A. In conclusion, supplemental protein has no negative effect on renal function of preterm infants and does not alter renal parameters. Therefore, physicians of ELBW and VLBW infants are recommended to do not underestimate the crucial role of nutrition for their specific patients.

\section{List of acronyms}

ALB - Albumin

BUN - Blood Urea Nitrogen

CBUN - Corrected Blood Urea Nitrogen

$\mathrm{Cr}$ - Creatinine

ELBW - Extremely Low Birth Weight

IRCT - Iranian Registry of Clinical Trials

NICU - Neonatal Intensive Care Unit

RCT - Registry of Clinical Trials

U/A - Urine analysis, Urinanalys

VLBW - Very Low Birth Weight

\section{Author's contributions}

All authors played a substantial role in data acquisition and analysis, and also in conception and revision of the manuscript.

\section{Acknowledgments}

The authors thank the Shahid Akbarabadi Clinical Research Development Unit (ShACRDU), Iran University of Medical Sciences (IUMS), Tehran, Iran for their help, and cooperation throughout the period of the study.

\section{Funding}

There was no funding support for this study.

\section{Conflict of Interest}

The authors have no conflicts to disclose.

Ethical Publication Statement

We confirm that we have read the Journal's position on issues involved in ethical publication and affirm that this report is consistent with those guidelines.

\section{Corresponding Author}

Mandana Kashaki, Shahid Akbarabadi Clinical Research Development Unit, Iran University of Medical Sciences, Tehran, Iran. Phone:+ 982155633244

Email: Kashaki.m@iums.ac.ir

E-mails of co-authors

Arash Bordbar: Bordbar.a@iums.ac.ir Azade Noroozi Vahid: azadenoroozi612@gmail.com

\section{References}

1. Lin HJ, Du LZ, Ma XL, et al. Mortality and Morbidity of Extremely Low Birth Weight Infants in the Mainland of China: A Multi-center Study. Chin Med J (Engl) 2015;128:2743-50. doi:10.4103/0366-6999.167312

2. Morrison J, Riggs K, Rurak D. Fluoxetine during pregnancy: Impact on fetal development. Reproduction, fertility, and development 2005;17:641-50. 10.1071/RD05030.

3. Puntis JW. Nutritional support in the premature newborn. Postgrad Med J 2006;82:192-8. doi:10.1136/pgmj.2005.038109

4. Denney L, Afeiche MC, Eldridge AL, et al. Food Sources of Energy and Nutrients in Infants, Toddlers, and Young Children from the Mexican National Health and Nutrition Survey 2012. Nutrients 2017;9:494. doi:10.3390/nu9050494

5. de Koning TJ. Amino acid synthesis deficiencies. J Inherit Metab Dis 2017;40:609-20. doi:10.1007/ s10545-017-0063-1

6. Park SY, Kim TJ, Kim MJ. Acute hyperkalemia induced by hyperglycemia in non-diabetic patient. Korean J Anesthesiol 2011;61:175-6. doi:10.4097/ kjae.2011.61.2.175.

7. Underwood MA. Human milk for the premature infant. Pediatr Clin North Am 2013;60:189-207. doi:10.1016/j.pcl.2012.09.008.

8. Behrman RE, Kliegman RM, Jenson HB. Nelson text book of pediatrics, 19th ed .Philadelphia: WB Saunders, 2011.

9. Hair AB, Hawthorne KM ,Chetta KE, Abrams SA. Human milk feeding supports adequate growth grams birth weight. BMC Res Notes 2013,6:459.

10. Yigit S, Akgoz A, Memisoglu A, et al. Breast milk fortification: effect on gastric emptying . J Matern Fetal Neonatal Med 2008:21:843-6. 


\section{Renal function in the third year of birth}

Eur J Transl Myol 30 (2): 304-310, 2020

11. Alan S, Atasay B, Cakir U,et al. An intention to achieve better postnatal in-hospital-growth for preterm infants: Adjustable protein fortification of human milk. Early Hum Dev 2013 Dec; 89:101723.

12. Embleton ND, Simmer K. Practice of parenteral nutrition in VLBW and ELBW infants. World Rev Nutr Diet 2014;110:177-89.

13. Biasini A, Marvulli L, Neri E, et al. Growth and neurological outcome in ELBW preterms fed with human milk and extra-protein supplementation as routine practice: do we need further evidence? J Matern Fetal Neonatal Med 2012,25 suppl 4:72-4.

14. Kashaki, M., Mazouri, A., Bordbar, A., et al. Effect of Protein Supplementation on the Growth of Infants Weighing Less than 1,000 Grams Hospitalized on the Neonatal Intensive Care Unit of Akbar Abadi Hospital in Tehran, Iran (2015-2016). Iranian Journal of Neonatology 2018;9:49-56. doi: 10.22038/ijn.2018.27558.1368.

15. Hay WW Jr. Nutritional Support Strategies for the Preterm Infant in the Neonatal Intensive Care Unit Pediatr Gastroenterol Hepatol Nutr 2018;21:23447. doi:10.5223/pghn.2018.21.4.234

16. Morgan $\mathrm{C}$, McGowan $\mathrm{P}$, Herwitker $\mathrm{S}$, et al. Postnatal head growth in preterm infants: a randomized controlled parenteral nutrition study. Pediatrics 2014;133 e120-8.10.1542/peds.20132207

17. Kumar P, Sundaram V. Protein Supplementation of Human Milk for Promoting Growth in Preterm Infants.. Cochrane Review 2011;CD000433.

18. Nagaya K, Tanaka S, Kitajima H, Fujimura M. The corrected blood urea nitrogen predicts the developmental quotient of extremely low-birth- weight infants at the corrected age of 36 months. Early Human Development 2007;83:285-91.

19. Radmacher PG, Lewis SL, Adamkin DH. Early amino acids and the metabolic response of ELBW infants $(1000 \mathrm{~g})$ in three time periods. Journal of Perinatology 2009;29:433-7.

20. Stritzke A, Sumesh T, Harish A, et al. Renal consequences of preterm birth. Molecular and Cellular Pediatrics 2017;4. 10.1186/s40348-0160068-0.

21. Seki M, Nakayama M, Sakoh T, et al. Blood urea nitrogen is independently associated with renal outcomes in Japanese patients with stage 3-5 chronic kidney disease: a prospective observational study. BMC Nephrol 2019;20:115. doi:10.1186/s 12882-019-1306-1

22. Gowda S, Desai PB, Kulkarni SS, et al. Markers of renal function tests. N Am J Med Sci 2010;2:170-3.

23. Lang J, Katz R, Ix JH, et al. Association of serum albumin levels with kidney function decline and incident chronic kidney disease in elders. Nephrology Dialysis Transplantation 2018;33:98692. https://doi.org/10.1093/ndt/gfx229

24. Delanghe J, Speeckaert M. Preanalytical requirements of urinalysis. Biochem Med (Zagreb) 2014;24:89-104. doi:10.11613/BM.2014.011

25. Kashaki M, Masoudi Samghabadi F, Bordbar A. Effect of Fortification of Breast Milk in Conjugation with Protein Supplement on Neurodevelopment of Preterm Low Birth Weight Infants at 3 Years. Med Arch 2019;73:344-50.

Submission: Novamber, 6, 2019

Acceptance: December 12, 2019 